\title{
Panorama da produçáo científica sobre terapia ocupacional e saúde mental (1990-2018): estudo bibliométrico
}

\section{Overview of scientific production on occupational therapy and mental health (1990-2018): a bibliometric study}

\section{Lisabelle Manente Mazaro $^{a}$ (D), Bárbara de Fátima Depole ${ }^{a}$ (D), Danieli Amanda Gasparini ${ }^{\mathrm{a}}$ (D),} Erika Regina de Oliveira Colato ${ }^{a}$ (D), Laysla Demonari Gomes ${ }^{a}$ (D),

Marina Batista Chaves Azevedo de Souza ${ }^{a}$ (D), Thaís Thaler Souza ${ }^{a}$ (D), Thelma Simôes Matsukura ${ }^{a}$ (D), Isabela Aparecida de Oliveira Lussia ${ }^{\text {(D) }}$

${ }^{a}$ Universidade Federal de São Carlos - UFSCar, São Carlos, SP, Brasil.

Como citar: Mazaro, L. M., Depole, B. F., Gasparini, D. A., Colato, E. R. O., Gomes, L. D., Souza, M. B. C. A., Souza, T. T., Matsukura, T. S., \& Lussi, I. A. O. (2021). Panorama da produção científica sobre terapia ocupacional e saúde mental (1990-2018): estudo bibliométrico. Cadernos Brasileiros de Terapia Ocupacional, 29, e2855. https://doi.org/10.1590/2526-8910.ctoAR2159

\begin{abstract}
$\underline{\text { Resumo }}$
Introduçáo: Diante das sucessivas transformações no que se refere à assistência em saúde mental e às abordagens teóricas que ancoram as práticas não apenas no Brasil, mas no mundo inteiro, percebe-se a importância de sistematizar e identificar o que tem sido produzido e divulgado por terapeutas ocupacionais sobre esta temática. Objetivo: Descrever o panorama do conhecimento científico sobre terapia ocupacional e saúde mental, levando em consideração as variáveis ano, idioma, país, abordagem metodológica e objeto dos estudos. Método: Trata-se de uma pesquisa exploratória e descritiva, de abordagem quantitativa, que se utiliza de estratégia bibliométrica para sistematizar os resultados encontrados. Resultados: Foram analisados 249 estudos, sendo perceptível maior incidência de artigos brasileiros, australianos, estadunidenses e canadenses, publicados em inglês e, principalmente, a partir da década de 2000. A abordagem metodológica predominante foi a qualitativa e foram construídas nove categorias que dispóem sobre os objetos dos estudos. Conclusáo: Os resultados do mapeamento sobre a produção científica da terapia ocupacional em saúde mental possibilitaram a identificação de interesses e tendências teóricas e práticas ao longo do tempo e a nível mundial, assim como realçaram a importância da profissão neste campo.
\end{abstract}

Palavras-chave: Literatura de Revisão, Saúde Mental, Terapia Ocupacional/Tendências. 


\begin{abstract}
$\underline{\text { Abstract }}$
Introduction: The successive transformations in mental health practices and theoretical approaches in Occupational Therapy, both in Brazil and worldwide, give rise to the need of systematizing and identifying what has been produced and disseminated by occupational therapists on this topic. Objectives: To describe the panorama of scientific productions about Occupational Therapy and mental health, considering variables such as year, language, country, methodological approach, and object of the studies. Method: This exploratory and descriptive research was based on a quantitative approach, using bibliometric analysis to systematize its data. Results: 249 studies were analyzed that demonstrate the highest incidence of Brazilian, Australian, American, and Canadian articles, published in English and mainly from the 2000s onwards. The predominant methodological approach was qualitative, and nine categories were created to deal with the objects of the studies. Conclusion: The results of the mapping of Occupational Therapy scientific production in mental health enabled the identification of theoretical and practical interests and trends over time worldwide.
\end{abstract}

Keywords: Review, Mental Health, Occupational Therapy/Trends.

\title{
Introduçáo
}

Historicamente, a terapia ocupacional e a saúde mental percorreram trajetórias práticas e teóricas que se iniciam no campo asilar e na tradição psiquiátrica, indo em direção à assistência no território e aos processos de desinstitucionalização. Diante disso, e em relação à construção do conhecimento científico em terapia ocupacional, identifica-se, no entanto, que é só a partir da década de 1990 que se percebe um investimento mundial na busca por uma consistência teórica e científica de práticas que já eram executadas como práticas de terapia ocupacional (Magalhães, 2013). Esclarece-se que a busca pela legitimidade científica ocorre de maneira diferente nos diversos lugares do mundo.

A história da terapia ocupacional, da Saúde Mental e das construções críticas e de direitos humanos na América Latina dizem de uma mesma narrativa e sofrem importantes mudanças, principalmente a partir da década de 80 , no Brasil. A profissão sempre esteve atrelada às lutas e aos movimentos populares e, no Brasil, com a conquista da democracia, os terapeutas ocupacionais, descontentes com a perspectiva reducionista da profissão, a qual estava centralizada em um paradigma reabilitador, passam a desenvolver práticas que direcionam a uma transformação social e assumem um compromisso ético e político com essas questóes (Guajardo Córdoba \& Galheigo, 2015).

Com isso, a construção do conhecimento científico em terapia ocupacional, articulado ao campo da Saúde Mental, é fortemente atravessada por questóes sociopolíticas. No Brasil, aponta-se que, acompanhando o movimento da Reforma Psiquiátrica, as açóes voltadas para esse campo assumiram uma concepção ampliada, condizente com a evolução do próprio conceito de saúde, construído na perspectiva de açóes territoriais, intersetoriais, sob a égide do paradigma psicossocial. Princípios como democratização, participação social, envolvimento, corresponsabilização, acolhimento, escuta polifônica e transversalidade atualmente direcionam o cuidado e atenção ao cotidiano psicossocial e das intervençôes dentro desta clínica (Amarante, 2007). 
Diante disso, entende-se que a assistência em saúde mental e as abordagens teóricas que ancoram as práticas náo apenas no Brasil, mas no mundo todo, transformaram-se ao longo do tempo. Assim, tem-se buscado aprimorar teorias e técnicas para a atuaçáo em serviços de saúde mental (Ribeiro \& Oliveira, 2005). Acrescenta-se ainda que os terapeutas ocupacionais que estudam e intervêm em saúde mental buscam cada vez mais compreendêla enquanto campo de atuação e de produçáo de saber, procurando aprimorar conhecimentos específicos em terapia ocupacional dentro desse campo (Morato \& Lussi, 2018).

No Brasil, tendo a Atençáo Psicossocial como direcionadora de suas açóes, a terapia ocupacional utiliza de sua especificidade e ressignifica o conceito de atividade, não de forma a controlar ou a eliminar o sofrimento psíquico, mas de modo a contribuir com a emancipação individual e coletiva, possibilitando formas novas e criativas de existir (Ribeiro \& Machado, 2008).

Assim, com base na compreensão de que as açôes de intervenção, referenciais teóricos e reflexóes relativas à terapia ocupacional no campo da saúde mental estáo presentes na literatura da área e podem contribuir para a contextualização e revelação do estado da arte neste campo, considera-se a relevância de sistematizar e identificar o que tem sido produzido e divulgado por terapeutas ocupacionais em periódicos da área.

Aponta-se que, a partir do momento em que mudanças importantes ocorreram nas abordagens teóricas e nas práticas assistenciais em terapia ocupacional e saúde mental no mundo, as produçóes que objetivam mapear e descrever conhecimentos científicos ao longo do tempo se tornaram interessantes na composição do arcabouço teórico sobre o tema. Assim, este estudo teve como objetivo descrever o panorama do conhecimento científico sobre terapia ocupacional e saúde mental.

Produçôes dessa natureza auxiliam na compreensão das transformaçóes ocorridas sobre o tema estudado, uma vez que se propóe a analisar publicaçóes elaboradas por diferentes pesquisadores, em diferentes locais, contextos históricos, periódicos científicos ou idiomas. Da mesma forma, constata-se que, por meio de estudos como esses, é possível não apenas identificar mudanças na teoria e prática profissional, mas também identificar tendências mundiais sobre o assunto; os principais autores e periódicos que se dedicam a produzir sobre o tema; compreender a incidência das diferentes abordagens metodológicas e objetos de estudo. Assim, pode-se descrever uma agenda de pesquisa contemporânea baseada em possíveis lacunas científicas encontradas.

\section{Método}

Trata-se de uma pesquisa exploratória e descritiva, de abordagem quantitativa e que se utiliza de estratégia bibliométrica para sistematizar os resultados encontrados. Esclarece-se que bibliometria surgiu como uma metodologia de pesquisa diante da crescente necessidade de compreender e avaliar as atividades de produção científica. Atualmente, os estudos considerados bibliométricos podem estar fundamentados em procedimentos estatísticos, leis e princípios matemáticos específicos, e têm o objetivo de analisar e mensurar a qualidade e o impacto de estudos científicos por meio destes princípios (Pimenta et al., 2017).

Todavia, ao longo do tempo, autores que produzem revisóes da literatura que têm o objetivo de mapear, sintetizar, sistematizar e analisar a produção científica sobre um tema 
específico - considerando quem produz, onde produz, onde publica o estudo, sobre o que produz, entre outras variáveis - vêm identificando seus estudos como sendo do tipo descritivo, de abordagem quantitativa, com a utilização de estratégia bibliométrica ou da técnica da bibliometria para descrever e sistematizar os dados de variáveis escolhidas, sem obrigatoriamente avaliar o impacto das publicaçóes por meio de princípios matemáticos, como fazem os estudos bibliométricos que utilizam a perspectiva tradicional (Brilhante et al., 2016; Silva \& Hayashi, 2018; Hayashi, 2013).

Desta forma, esclarece-se que a bibliometria foi aqui utilizada em uma perspectiva similar à do estudo de Brilhante et al. (2016), apontando que a bibliometria é indicada para favorecer prognósticos acerca de processos de investigação e comunicação escrita de um determinado tema.

Para coleta de dados, foram selecionados artigos publicados no período de 1990 a 2018. O ano de 1990 foi escolhido porque os Cadernos Brasileiros de Terapia Ocupacional, um periódico eletrônico brasileiro importante, começou sua indexação eletrônica apenas a partir deste ano. Ainda, os volumes de 1990 a 2001 da Revista de Terapia Ocupacional da USP não foram incluídos nas buscas, por estarem disponíveis apenas na forma impressa. Já o ano de 2018 foi escolhido porque, no momento de realização da pesquisa, estávamos ainda vivenciando o ano de $2019^{1}$.

As bases de dados em que ocorreram as buscas foram: BVS, Scopus e Scielo. Como a indexação dos periódicos nacionais específicos de terapia ocupacional nas bases explicitadas é recente, as pesquisadoras optaram por realizar também a busca diretamente no site desses periódicos, a saber: Cadernos Brasileiros de Terapia Ocupacional, Revista de Terapia Ocupacional da USP, Revista Baiana de Terapia Ocupacional e Revisbrato. Como já citado, nas revistas, foram selecionados artigos publicados no período entre 1990 e 2018, que estão disponíveis online, no site desses periódicos. Assim, os volumes de 1990 a 2001 da Revista de Terapia Ocupacional da USP não foram incluídos nas buscas, por estarem disponíveis apenas na forma impressa. É necessário esclarecer que, diferente das bases indexadas, os sistemas de busca dos sites dos periódicos têm um refinamento frágil, já que não funcionam por meio de operadores booleanos e de outros códigos expostos em manuais de codificação - como apresentam as bases consultadas - o que implicou longas análises manuais.

Para realizar as buscas, foram utilizados os descritores: "occupational therapy" e "mental health”, seus plurais, sinônimos, derivaçóes, e os operadores booleanos responsáveis por informar ao sistema de busca os termos combinados entre si. Os sinônimos e derivaçóes de "occupational therapy" e "mental health" foram estabelecidos neste estudo por meio dos vocabulários padronizados da Biblioteca Virtual em Saúde (Descritores em Ciências da Saúde - DECs) e da Biblioteca Nacional de Medicina dos Estados Unidos (Medical Subject Headings - MESH).

Desta forma, foram elaboradas as seguintes expressóes de busca: a) "occupational therapist" OR "occupational therapists" OR "occupational therapy" AND "mental health"; b) "occupational therapist" OR "occupational therapists" OR "occupational therapy" AND "psychiatry"; c) "occupational therapist" OR "occupational therapists" OR

\footnotetext{
${ }^{1}$ A finalização do processo metodológico deste estudo bibliométrico ocorreu no ano de 2019 e sua construção foi produto de uma disciplina intitulada "Terapia ocupacional em Saúde Mental e Atençấo Psicossocial”, ministrada no Programa de Pós-Graduaçăo em Terapia Ocupacional da UFSCar nesse mesmo ano, cujo objetivo era estudar referenciais teóricos clássicos e contemporâneos em saúde mental.
} 
"occupational therapy" AND "mental illness"; d) "occupational therapist" OR "occupational therapists" OR "occupational therapy" AND "mental disorders"; e) "occupational therapist" OR "occupational therapists" OR "occupational therapy" AND "mental suffering"; f) "occupational therapist" OR "occupational therapists" OR "occupational therapy" AND autism; g) "occupational therapist" OR "occupational therapists" OR "occupational therapy" AND autistic; h) "occupational therapist" OR "occupational therapists" OR "occupational therapy” AND asperger.

A inserção de dois descritores relacionados ao diagnóstico na busca, "autistic" e "asperger", ocorreu por observar, nas produçóes científicas, que esses termos apareciam distanciados da saúde mental, como representantes de um subgrupo dentro da saúde mental. Diante disso, o grupo de pesquisadoras optou por acrescentar esses diagnósticos de maneira isolada para observar o alcance dessas produçóes.

Os critérios de inclusão pré-estabelecidos foram: a) ser um manuscrito do tipo artigo científico; b) artigos em que os dois descritores (ou um de seus sinônimos, plurais e derivaçóes) da expressão de busca estivessem no título, resumo ou nas palavras-chave; c) artigos que apresentavam como tema central do estudo a terapia ocupacional e a saúde mental; d) artigos escritos nos idiomas inglês, português e espanhol. Com relação aos critérios de exclusão, têm-se: a) artigos de revisão da literatura; b) artigos não disponíveis online; c) artigos sem o manuscrito disponível na íntegra para acesso gratuito. Enfatizamos que o foco das autoras era traçar o panorama de produção do conhecimento disponível exclusivamente em artigos científicos publicados em periódicos revisados por pares. Assim, livros e capítulos de livros, bem como a literatura cinza, não foram contemplados.

Os dados coletados foram inseridos em uma planilha do Microsoft Excel, que continha as seguintes informaçôes ou variáveis: base de dados; título; autores e suas afiliaçôes; periódico; ano de publicação; palavras-chave; objetivos; objeto do estudo; tipo de estudo e abordagem; metodologia; país de origem (local onde o estudo foi realizado); serviços vinculados; participantes; principais conceitos; referenciais teóricos; principais resultados e link do artigo. Aponta-se que, especificamente neste artigo, serão feitas descrições e discussóes acerca de algumas das variáveis contidas na planilha, a saber: ano de publicação, periódicos, abordagens metodológicas, país de origem e objetos de estudo.

Inicialmente, foram identificados 765 artigos. Destes, 441 em inglês, 299 estavam em português, e 25 em espanhol. Foram excluídos 223 artigos duplicados e 28 artigos de revisão. Ainda que tenha sido utilizado o sistema de comutação da Biblioteca Comunitária da UFSCar para acesso aos artigos pagos, alguns periódicos responderam negativamente ao pedido de acesso da Biblioteca. Assim, 16 artigos foram excluídos por não terem sido contemplados por esse sistema. Encerrada esta etapa, permaneceram no estudo um total de 498 artigos (333 em inglês, 143 em português, 22 em espanhol).

$\mathrm{Na}$ etapa seguinte, foram lidos os resumos dos 498 artigos, com o objetivo de selecionar aqueles que, de fato, dedicam-se a refletir sobre questóes voltadas à terapia ocupacional e sua articulação com a saúde mental. Nesta etapa, foram excluídos 195 estudos, seja pela ausência dos dois descritores bases (seus sinônimos, plurais e derivações) no título, resumo ou palavras-chave, seja por serem estudos cujos resumos não proporcionaram compreender que existia uma interlocução entre terapia ocupacional e saúde mental.

$\mathrm{Na}$ etapa seguinte, os 303 artigos restantes foram lidos na íntegra, de forma a preencher a planilha com todas as informaçóes dos artigos. Ao final desta etapa, ainda foram excluídos 54 artigos que, na análise dos manuscritos completos, identificou-se que o tema terapia 
ocupacional e saúde mental não era o tema central do estudo. Podemos citar como exemplos os artigos que trazem a terapia ocupacional apenas como um descritor (artigos em que a profissão não foi mencionada ao longo do texto); aqueles nos quais os terapeutas ocupacionais são participantes do estudo, especialmente em sua atuação em uma equipe multiprofissional; aqueles que apresentam a visão de outros profissionais sobre a atuação do terapeuta ocupacional; aqueles que se dedicam ao estudo de patologias diversas e as possíveis repercussóes na saúde mental do indivíduo; aqueles que refletem sobre a atuaçáo da terapia ocupacional de forma geral, sem se aprofundar no campo da saúde mental, e aqueles que refletem sobre questóes de saúde mental sem estarem diretamente relacionados à atuação do terapeuta ocupacional.

Permaneceram 249 artigos na análise, sendo este o número final de artigos: 153 (61\%) publicados em inglês, 89 (36\%) em português e 7 (3\%) em espanhol. A Figura 1, a seguir, indica o número de produções excluídas e os motivos desta exclusão:

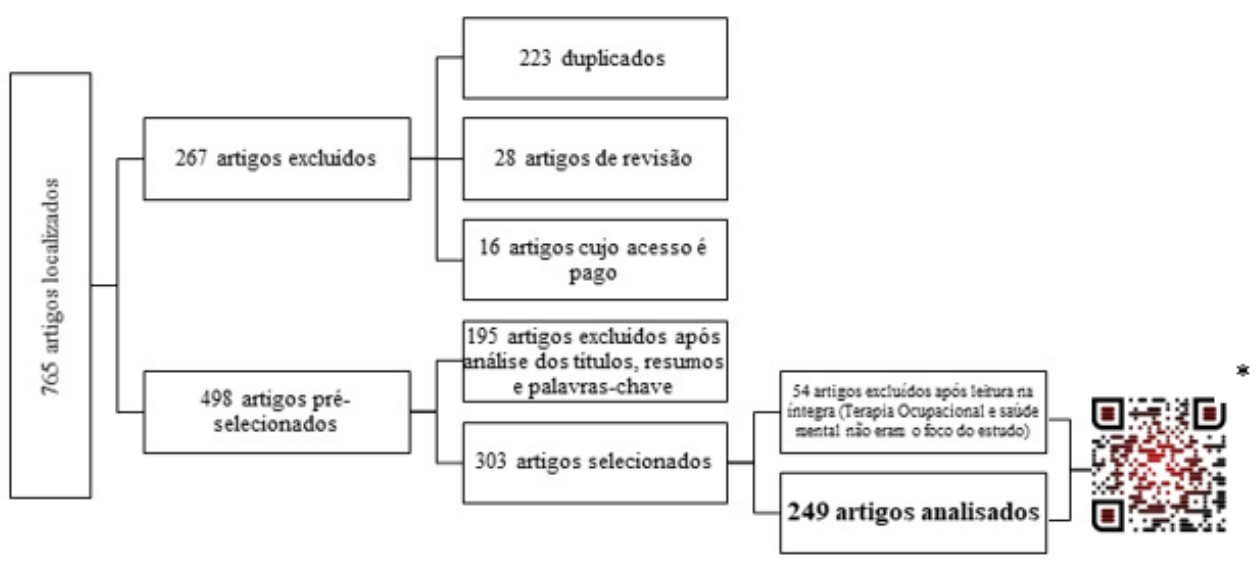

Figura 1. Fluxograma do processo de seleção dos estudos. Fonte: Elaboração própria, 2020. ${ }^{*} \mathrm{O} Q R$ Code permite o acesso às informaçóes sobre os artigos analisados neste estudo e pode ser acessado por meio de aplicativos baixados em celular smartphone ou tablet compatível. Basta abrir a câmera e apontála para o código QR e seguir as orientaçóes que o celular ou tablet irá fornecer.

\section{Resultados e Discussóes}

A seguir, com base na estratégia bibliométrica, os resultados foram organizados e sistematizados em tópicos, que representam as variáveis elencadas para serem discutidas neste artigo (ano, idioma e país; abordagem metodológica e objeto dos estudos). Ao final, um último tópico foi dedicado às reflexóes específicas sobre os objetos dos estudos analisados. Nesta sessão, os artigos analisados serão citados por meio de um número de identificaçáo e o acesso a eles pode ser obtido por meio do QR Code.

\section{Ano de publicação, idioma e país de origem dos estudos}

A Tabela 1 apresenta a distribuição dos artigos com base nas variáveis ano de publicação, idioma e país de origem dos estudos. Os anos de publicação foram agrupados em décadas, tendo sido publicados 26 artigos (10\%) no período entre 1990 e 1999, 34 artigos (14\%) 
entre 2000 e 2009 , e 189 (76\%) entre 2010 e 2018 . Entre os idiomas, há destaque para a língua inglesa, com 153 estudos (61\%), seguida da língua portuguesa, com 89 (36\%), e 7 publicaçóes realizadas na língua espanhola, o que corresponde a 3\% do total. Já em relação aos países onde os estudos foram realizados, identificamos 87 desenvolvidos no Brasil, o que representa $35 \%$ do total. Isso faz com que o país se destaque com maior número de estudos realizados sobre o assunto.

Tabela 1. Distribuição dos artigos por ano de publicação, idioma e país de origem.

\begin{tabular}{|c|c|c|c|c|c|c|}
\hline \multirow{2}{*}{ Década } & \multirow{2}{*}{ Quantidade } & \multicolumn{3}{|c|}{ Idioma } & \multirow{2}{*}{ País de Origem } & \multirow{2}{*}{ Quantidade } \\
\hline & & Inglês & Português & Espanhol & & \\
\hline \multirow{5}{*}{ 1990-1999 } & \multirow{5}{*}{26} & \multirow{5}{*}{23} & \multirow{5}{*}{2} & \multirow{5}{*}{1} & Brasil & 2 \\
\hline & & & & & EUA & 11 \\
\hline & & & & & Canadá & 2 \\
\hline & & & & & Noruega & 1 \\
\hline & & & & & $\mathrm{N} / \mathrm{E}^{*}$ & 10 \\
\hline \multirow{7}{*}{$2000-2009$} & \multirow{7}{*}{34} & \multirow{7}{*}{18} & \multirow{7}{*}{16} & \multirow{7}{*}{0} & Brasil & 15 \\
\hline & & & & & Austrália & 4 \\
\hline & & & & & EUA & 1 \\
\hline & & & & & Canadá & 3 \\
\hline & & & & & China & 2 \\
\hline & & & & & Índia & 1 \\
\hline & & & & & $\mathrm{N} / \mathrm{E}^{*}$ & 8 \\
\hline \multirow{14}{*}{ 2010-2018 } & \multirow{14}{*}{189} & \multirow{14}{*}{112} & \multirow{14}{*}{71} & \multirow{14}{*}{6} & Brasil & 70 \\
\hline & & & & & Austrália & 25 \\
\hline & & & & & EUA & 12 \\
\hline & & & & & Canadá & 5 \\
\hline & & & & & Suécia & 8 \\
\hline & & & & & África do Sul & 6 \\
\hline & & & & & Inglaterra & 4 \\
\hline & & & & & China & 2 \\
\hline & & & & & Chile & 2 \\
\hline & & & & & Japão & 2 \\
\hline & & & & & Israel & 2 \\
\hline & & & & & Outros** & 12 \\
\hline & & & & & Mais de um país*** & 10 \\
\hline & & & & & $\mathrm{N} / \mathrm{E}^{*}$ & 27 \\
\hline
\end{tabular}

Fonte: Elaboração própria, 2020. N/E*: Não Especificado. Outros**: País de origem que foi identificada apenas uma publicação. São eles: Argentina, Colômbia, Coreia do Sul, Espanha, Índia, Irã, Irlanda, Noruega, Nova Zelândia, Polônia, Porto Rico e Turquia. Mais de um país***: estudos que foram desenvolvidos concomitantemente em mais de um país.

Destacamos, na tabela anterior, o aumento significativo dos estudos, especialmente nos últimos anos, refletindo o crescimento da pesquisa científica mundial na área da terapia ocupacional (Folha et al., 2019; Hahn \& Pinto, 1997). Apontamos, ainda, que os resultados do presente estudo evidenciam que a interlocução entre a terapia ocupacional e a saúde mental, possivelmente, acompanhou tal crescimento. 
Em relação ao predomínio dos artigos publicados em língua inglesa, identificamos que "[...] há uma tendência crescente da publicação de artigos na língua inglesa, reflexo do esforço de cientistas, instituições de ensino e periódicos de países não anglófonos em prol da internacionalização das suas produçóes científicas" (Cintra et al., 2020, p. 17).

Considerando o mercado altamente competitivo da produção científica atual e que um artigo pode ser publicado uma única vez, a busca pela publicação na língua inglesa tem sido realizada de maneira exaustiva, principalmente para os pesquisadores brasileiros, e está em acordo com uma tendência geral de produção científica, a qual procura ter um alcance maior de suas publicaçóes e atender um mercado acadêmico cada vez mais rigoroso (Cintra et al., 2020; Volpato, 2015).

No que concerne à construção do conhecimento em terapia ocupacional no Brasil, explicitamos o envolvimento dos terapeutas ocupacionais brasileiros com o campo da saúde mental, reforçando a realidade de sua inserção e o comprometimento com o desenvolvimento do conhecimento. Os terapeutas ocupacionais brasileiros desempenharam um papel relevante na luta antimanicomial, tanto no trabalho junto aos serviços substitutivos ao modelo asilar, como também no auxílio à construção de políticas públicas de atenção à saúde mental. Tais reflexôes repercutiram não apenas nas práticas assistenciais, como também nas formaçóes pós-graduadas e na produção científica desses profissionais (Ricci et al., 2018).

Nessa perspectiva, a literatura aponta que a produção teórica desenvolvida ao longo do tempo por terapeutas ocupacionais brasileiros, sobre o cuidado e a assistência em saúde mental, é vasta (Almeida \& Trevisan, 2010; Ricci et al., 2018). Identificamos que tal constatação corrobora os achados do presente estudo.

Apontamos, ainda, que grande parte dos estudos se apresentam como resultados de pesquisas decorrentes da formação acadêmica, seja ela em nível de graduação ou de pósgraduação. Nesse sentido, ressaltamos que os cursos de graduação em terapia ocupacional aumentaram sobremaneira a partir da década de 1970, e que, a partir desse momento, os terapeutas ocupacionais perceberam que as especializaçóes e aprimoramentos eram a soluçáo em termos de formação pós-graduada, seguidos dos programas de mestrado, doutorado e estágios pós-doutorais em áreas diversas, inicialmente fora da terapia ocupacional (Malfitano et al., 2013).

O ano de 1970 registrou a primeira obtenção de um grau de mestre por um terapeuta ocupacional no Brasil. Em 1981, houve a conclusão do primeiro doutorado. Então, foi somente a partir do final da década de 1980 que começou a ocorrer o aumento gradual na formação de mestres na área, e, na década de 1990, de doutores. É importante explicitar que aproximadamente $90 \%$ do quantitativo atual de mestres e doutores obteve a titulaçáo apenas entre os anos 2000 e 2017 (Folha, 2019).

O primeiro programa de pós-graduação na área de terapia ocupacional da América do Sul foi criado em 2010, compondo a Área de Educação Física, Fonoaudiologia, Fisioterapia e Terapia Ocupacional, sendo denominado Programa de Pós-Graduação de Terapia Ocupacional (PPGTO) da Universidade Federal de São Carlos (UFSCar). À época, já se apontava que um programa de pós-graduação tem a função de produzir novos pesquisadores e novos conhecimentos, multiplicando ideias e contribuindo para o crescimento e a disseminaçáo do conhecimento científico (Malfitano et al., 2013).

Assim, acreditamos que o aumento dos estudos brasileiros, ao longo do tempo, pode ter vinculação com o surgimento da formação pós-graduada específica da área, e com o maior 
interesse dos terapeutas ocupacionais em realizá-la. Destaca-se que o investimento estatal em programas de pós-graduação da área oferecerem, ainda, condiçốes de inserção e permanência dos pesquisadores nesses programas. Tal importância se deve ao fato de que esses investimentos podem beneficiar a população, que usufrui de práticas em terapia ocupacional e Saúde Mental desenvolvidas por meio do conhecimento produzido durante essas formaçóes.

No que diz respeito à construção do conhecimento em terapia ocupacional no cenário internacional, identificamos uma realidade diferente da brasileira. Nos artigos internacionais, os autores não necessariamente estão ligados a programas de pós-graduação - grande parte da afiliaçáo sáo os próprios serviços de saúde mental - e os estudos informam sobre a prática profissional, havendo diálogo e proximidade entre a difusão científica e o exercício da clínica profissional em saúde mental. O cuidado ofertado aos usuários é renovado com a reflexão sobre a prática profissional e a apreensão de novos conhecimentos construídos.

No cenário nacional, as publicaçóes estão mais direcionadas à implementação das políticas públicas, à estrutura do SUS e ao desenvolvimento de suas açóes, analisando, principalmente, programas que têm como público-alvo os coletivos e não os atendimentos individualizados. Internacionalmente, a literatura trata principalmente das intervenções focadas no indivíduo e em práticas profissionais não necessariamente ligadas a políticas públicas.

A Tabela 2, a seguir, apresenta as informaçóes relativas ao país de origem, aos periódicos e aos idiomas em que foram publicados os artigos analisados.

Tabela 2. Distribuição dos artigos segundo o país de origem dos estudos, o idioma, os periódicos e o ano de publicação.

\begin{tabular}{|c|c|c|c|c|c|c|c|}
\hline \multirow[b]{2}{*}{ País de Origem } & \multirow[b]{2}{*}{$\mathbf{n}$} & \multicolumn{3}{|c|}{ Idioma de Publicaçáo } & \multicolumn{3}{|c|}{ Ano de Publicaçáo } \\
\hline & & Inglês & Português & Espanhol & $\begin{array}{l}1990- \\
1999\end{array}$ & $\begin{array}{l}2000- \\
2009\end{array}$ & $\begin{array}{l}2010- \\
2018\end{array}$ \\
\hline BRASIL & 87 & & 86 & 1 & 2 & 15 & 70 \\
\hline $\begin{array}{l}\text { Cadernos Brasileiros de Ter. } \\
\text { Ocup. }\end{array}$ & 41 & & 40 & 1 & 1 & 6 & 34 \\
\hline Revista de Ter. Ocup. da USP & 36 & & 36 & & 1 & 9 & 26 \\
\hline REVISBRATO & 6 & & 6 & & & & 6 \\
\hline Ciência \& Saúde Coletiva & 1 & & 1 & & & & 1 \\
\hline Cogitare Enferm & 1 & & 1 & & & & 1 \\
\hline Revista Baiana de Ter. Ocup. & 1 & & 1 & & & & 1 \\
\hline Texto Contexto Enferm & 1 & & 1 & & & & 1 \\
\hline AUSTRÁLIA & 29 & 29 & & & $\mathbf{0}$ & 4 & 25 \\
\hline $\begin{array}{c}\text { Australian Occupational Therapy } \\
\text { Journal }\end{array}$ & 18 & 18 & & & & 3 & 15 \\
\hline $\begin{array}{c}\text { Scandinavian Journal of } \\
\text { Occupational Therapy }\end{array}$ & 3 & 3 & & & & & 3 \\
\hline $\begin{array}{l}\text { The American Journal of } \\
\text { Occupational Therapy }\end{array}$ & 2 & 2 & & & & & 2 \\
\hline $\begin{array}{c}\text { Occupational Therapy } \\
\text { International }\end{array}$ & 2 & 2 & & & & & 2 \\
\hline $\begin{array}{c}\text { Occupational Therapy Health } \\
\text { Care }\end{array}$ & 1 & 1 & & & & 1 & \\
\hline $\begin{array}{l}\text { Canadian Journal of } \\
\text { Occupational Therapy }\end{array}$ & 1 & 1 & & & & & 1 \\
\hline Psychiatric Quarterly & 1 & 1 & & & & & 1 \\
\hline
\end{tabular}


Tabela 2. Continuação...

\begin{tabular}{|c|c|c|c|c|c|c|c|}
\hline \multirow[b]{2}{*}{ País de Origem } & \multirow[b]{2}{*}{$\mathbf{n}$} & \multicolumn{3}{|c|}{ Idioma de Publicaçáo } & \multicolumn{3}{|c|}{ Ano de Publicaçáo } \\
\hline & & Inglês & Português & Espanhol & $\begin{array}{l}1990- \\
1999\end{array}$ & $\begin{array}{l}2000- \\
2009\end{array}$ & $\begin{array}{l}2010- \\
2018\end{array}$ \\
\hline Psychiatry Res & 1 & 1 & & & & & 1 \\
\hline EUA & 24 & 24 & & & 11 & 1 & 12 \\
\hline $\begin{array}{l}\text { The American Journal of } \\
\text { Occupational Therapy }\end{array}$ & 15 & 15 & & & 9 & & 6 \\
\hline $\begin{array}{c}\text { Occupational Therapy Health } \\
\text { Care }\end{array}$ & 3 & 3 & & & 1 & 1 & 1 \\
\hline $\begin{array}{l}\text { Occupational Therapy } \\
\text { International }\end{array}$ & 2 & 2 & & & 1 & & 1 \\
\hline J Epidemiol Community Health & 1 & 1 & & & & & 1 \\
\hline Hand (NY) & 1 & 1 & & & & & 1 \\
\hline $\begin{array}{l}\text { Community Ment Health } \\
\text { Journal }\end{array}$ & 1 & 1 & & & & & 1 \\
\hline Work & 1 & 1 & & & & & 1 \\
\hline CANADÁ & 10 & 10 & & & 2 & 3 & 5 \\
\hline $\begin{array}{l}\text { The American Journal of } \\
\text { Occupational Therapy }\end{array}$ & 7 & 7 & & & 2 & 3 & 2 \\
\hline $\begin{array}{l}\text { Canadian Journal of } \\
\text { Occupational Therapy }\end{array}$ & 2 & 2 & & & & & 2 \\
\hline $\begin{array}{l}\text { Occupational Therapy } \\
\text { International }\end{array}$ & 1 & 1 & & & & & 1 \\
\hline SUÉCIA & 8 & 8 & & & $\mathbf{0}$ & $\mathbf{0}$ & 8 \\
\hline $\begin{array}{l}\text { Scandinavian Journal of } \\
\text { Occupational Therapy }\end{array}$ & 5 & 5 & & & & & 5 \\
\hline $\begin{array}{l}\text { The American Journal of } \\
\text { Occupational Therapy }\end{array}$ & 1 & 1 & & & & & 1 \\
\hline $\begin{array}{l}\text { International Journal of } \\
\text { Qualitative Studies on Health } \\
\text { and Well-Being }\end{array}$ & 1 & 1 & & & & & 1 \\
\hline BMC Psychiatry & 1 & 1 & & & & & 1 \\
\hline ÁFRICA DO SUL & 6 & 6 & & & $\mathbf{0}$ & $\mathbf{0}$ & 6 \\
\hline $\begin{array}{l}\text { South African Journal of } \\
\text { Occupational Therapy }\end{array}$ & 6 & 6 & & & & & 6 \\
\hline INGLATERRA & 4 & 4 & & & 0 & 0 & 4 \\
\hline $\begin{array}{c}\text { Australian Occupational Therapy } \\
\text { Journal }\end{array}$ & 1 & 1 & & & & & 1 \\
\hline Journal of Mental Health & 1 & 1 & & & & & 1 \\
\hline Mental Illness & 1 & 1 & & & & & 1 \\
\hline $\begin{array}{l}\text { The American Journal of } \\
\text { Occupational Therapy }\end{array}$ & 1 & 1 & & & & & 1 \\
\hline CHINA & 4 & 4 & & & $\mathbf{0}$ & 2 & 2 \\
\hline $\begin{array}{l}\text { Occupational Therapy } \\
\text { International }\end{array}$ & 3 & 3 & & & & 2 & 1 \\
\hline Asian J Psychiatr & 1 & 1 & & & & & 1 \\
\hline CHILE & 2 & & & 2 & $\mathbf{0}$ & $\mathbf{0}$ & 2 \\
\hline $\begin{array}{c}\text { Revista Chilena de Terapia } \\
\text { Ocupacional }\end{array}$ & 2 & & & 2 & & & 2 \\
\hline JAPÃO & 2 & 2 & & & $\mathbf{0}$ & $\mathbf{0}$ & 2 \\
\hline
\end{tabular}


Tabela 2. Continuação...

\begin{tabular}{|c|c|c|c|c|c|c|c|}
\hline \multirow[b]{2}{*}{ País de Origem } & \multirow[b]{2}{*}{$\mathbf{n}$} & \multicolumn{3}{|c|}{ Idioma de Publicaçáo } & \multicolumn{3}{|c|}{ Ano de Publicaçáo } \\
\hline & & Inglês & Português & Espanhol & $\begin{array}{c}1990- \\
1999\end{array}$ & $\begin{array}{c}2000- \\
2009\end{array}$ & $\begin{array}{l}2010 \\
2018\end{array}$ \\
\hline $\begin{array}{l}\text { Hong Kong Journal of } \\
\text { Occupational Therapy }\end{array}$ & 2 & 2 & & & & & 2 \\
\hline ÍNDIA & 2 & 2 & & & $\mathbf{0}$ & 1 & 1 \\
\hline Indian Journal of Psychiatry & 1 & 1 & & & & 1 & \\
\hline $\begin{array}{c}\text { Disability, CBR and Inclusive } \\
\text { Development }\end{array}$ & 1 & 1 & & & & & 1 \\
\hline ISRAEL & 2 & 2 & & & $\mathbf{0}$ & $\mathbf{0}$ & 2 \\
\hline $\begin{array}{l}\text { The American Journal of } \\
\text { Occupational Therapy }\end{array}$ & 1 & 1 & & & & & 1 \\
\hline $\begin{array}{l}\text { Scandinavian Journal of } \\
\text { Occupational Therapy }\end{array}$ & 1 & 1 & & & & & 1 \\
\hline NORUEGA & 2 & 2 & & & 1 & $\mathbf{0}$ & 1 \\
\hline $\begin{array}{l}\text { Scandinavian Journal of } \\
\text { Occupational Therapy }\end{array}$ & 1 & 1 & & & 1 & & \\
\hline Sage Open & 1 & 1 & & & & & 1 \\
\hline ARGENTINA & 1 & & & 1 & $\mathbf{0}$ & $\mathbf{0}$ & 1 \\
\hline $\begin{array}{c}\text { Revista Chilena de Terapia } \\
\text { Ocupacional }\end{array}$ & 1 & & & 1 & & & 1 \\
\hline Colômbia & 1 & & & 1 & $\mathbf{0}$ & $\mathbf{0}$ & 1 \\
\hline Rev Colomb Psiquiatr & 1 & & & 1 & & & 1 \\
\hline COREIA DO SUL & 1 & 1 & & & $\mathbf{0}$ & $\mathbf{0}$ & 1 \\
\hline $\begin{array}{l}\text { Occupational Therapy } \\
\text { International }\end{array}$ & 1 & 1 & & & & & 1 \\
\hline ESPANHA & 1 & & & 1 & $\mathbf{0}$ & $\mathbf{0}$ & 1 \\
\hline $\begin{array}{c}\text { Cadernos Brasileiros de Terapia } \\
\text { Ocupacional }\end{array}$ & 1 & & & 1 & & & 1 \\
\hline IRÃ & 1 & 1 & & & $\mathbf{0}$ & $\mathbf{0}$ & 1 \\
\hline Japan Journal of Nursing Science & 1 & 1 & & & & & 1 \\
\hline IRLANDA & 1 & 1 & & & $\mathbf{0}$ & $\mathbf{0}$ & 1 \\
\hline $\begin{array}{l}\text { The American Journal of } \\
\text { Occupational Therapy }\end{array}$ & 1 & 1 & & & & & 1 \\
\hline NOVA ZELÂNDIA & 1 & 1 & & & $\mathbf{0}$ & $\mathbf{0}$ & 1 \\
\hline BMC Psychiatry & 1 & 1 & & & & & 1 \\
\hline POLÔNIA & 1 & 1 & & & $\mathbf{0}$ & $\mathbf{0}$ & 1 \\
\hline Postepy Rehabilitacji & 1 & 1 & & & & & 1 \\
\hline PORTO RICO & 1 & 1 & & & $\mathbf{0}$ & $\mathbf{0}$ & 1 \\
\hline $\begin{array}{l}\text { Occupational Therapy } \\
\text { International }\end{array}$ & 1 & 1 & & & & & 1 \\
\hline TURQUIA & 1 & 1 & & & $\mathbf{0}$ & $\mathbf{0}$ & 1 \\
\hline Noro Psikiyatr Ars & 1 & 1 & & & & & 1 \\
\hline MAIS DE UM PAÍS & 12 & 12 & & & $\mathbf{0}$ & $\mathbf{0}$ & 12 \\
\hline $\begin{array}{c}\text { Australian Occupational Therapy } \\
\text { Journal }\end{array}$ & 3 & 3 & & & & & 3 \\
\hline Frontiers Robotics & 1 & 1 & & & & & 1 \\
\hline $\begin{array}{l}\text { International Journal of Speech- } \\
\text { Language Pathology }\end{array}$ & 1 & 1 & & & & & 1 \\
\hline
\end{tabular}


Tabela 2. Continuação...

\begin{tabular}{|c|c|c|c|c|c|c|c|}
\hline \multirow[b]{2}{*}{ País de Origem } & \multirow[b]{2}{*}{$\mathbf{n}$} & \multicolumn{3}{|c|}{ Idioma de Publicaçáo } & \multicolumn{3}{|c|}{ Ano de Publicaçáo } \\
\hline & & Inglês & Português & Espanhol & $\begin{array}{c}1990- \\
1999\end{array}$ & $\begin{array}{c}2000- \\
2009\end{array}$ & $\begin{array}{c}2010- \\
2018\end{array}$ \\
\hline $\begin{array}{l}\text { Occupational Therapy } \\
\text { International }\end{array}$ & 2 & 2 & & & & & 2 \\
\hline Pilot and Feasibility Studies & 1 & 1 & & & & & 1 \\
\hline $\begin{array}{l}\text { Scandinavian Journal of } \\
\text { Occupational Therapy }\end{array}$ & 2 & 2 & & & & & 2 \\
\hline $\begin{array}{l}\text { The American Journal of } \\
\text { Occupational Therapy }\end{array}$ & 1 & 1 & & & & & 1 \\
\hline Work & 1 & 1 & & & & & 1 \\
\hline $\mathrm{N} / \mathrm{E}^{*}$ & 45 & 41 & 3 & 1 & 10 & 8 & 27 \\
\hline $\begin{array}{c}\text { African Journal of Primary } \\
\text { Health Care \& Family Medicine }\end{array}$ & 1 & 1 & & & & & 1 \\
\hline $\begin{array}{c}\text { Australian Occupational Therapy } \\
\text { Journal }\end{array}$ & 4 & 4 & & & & & 4 \\
\hline $\begin{array}{c}\text { Cadernos Brasileiros de Terapia } \\
\text { Ocupacional }\end{array}$ & 2 & & 2 & & 1 & & 1 \\
\hline $\begin{array}{l}\text { Health and Quality of Life } \\
\text { Outcomes }\end{array}$ & 1 & 1 & & & & & 1 \\
\hline $\begin{array}{l}\text { Hong Kong Journal of } \\
\text { Occupational Therapy }\end{array}$ & 2 & 2 & & & & & 2 \\
\hline Indian Journal of Psychiatry & 1 & 1 & & & & & 1 \\
\hline Int J Environ Res Public Health & 1 & 1 & & & & & 1 \\
\hline Irian Rehabilitation Journal & 1 & 1 & & & & & 1 \\
\hline Journal of Dual Diagnosis & 1 & 1 & & & & & 1 \\
\hline $\begin{array}{l}\text { Occupational Therapy } \\
\text { International }\end{array}$ & 4 & 4 & & & 2 & 1 & 1 \\
\hline $\begin{array}{c}\text { Psychiatric Rehabilitation } \\
\text { Journal }\end{array}$ & 1 & 1 & & & & 1 & \\
\hline Psychology \& Neuroscience & 1 & 1 & & & & & 1 \\
\hline $\begin{array}{c}\text { Revista Chilena de Terapia } \\
\text { Ocupacional }\end{array}$ & 1 & & & 1 & & & 1 \\
\hline Revista de TO da USP & 1 & & 1 & & & 1 & \\
\hline $\begin{array}{l}\text { Scandinavian Journal of } \\
\text { Occupational Therapy }\end{array}$ & 2 & 2 & & & & & 2 \\
\hline $\begin{array}{l}\text { The American Journal of } \\
\text { Occupational Therapy }\end{array}$ & 19 & 19 & & & 7 & 5 & 7 \\
\hline Work & 2 & 2 & & & & & 0 \\
\hline
\end{tabular}

Fonte: Elaboração própria, 2020. N/E*: Não Especificado.

Os artigos analisados foram publicados nos mais variados periódicos, com destaque para dois deles, The American Journal of Occupational Therapy, com 48 artigos (19\%), e Cadernos de Terapia Ocupacional da Universidade Federal de Sáo Carlos (UFSCar), atualmente intitulado Cadernos Brasileiros de Terapia Ocupacional, com 44 artigos (18\%). Juntos, eles publicaram $37 \%$ do total de artigos analisados.

A literatura aponta que, a partir da década de 1980, devido à difusão de periódicos considerados relevantes, como o Canadian Journal of Occupational Therapy e o American Journal of Occupational Therapy, foram iniciadas discussóes mundiais importantes acerca 
da legitimação do conhecimento em terapia ocupacional (Mângia, 1999). Além disso, os estudos identificados foram realizados em 23 países diferentes, o que expõe o interesse mundial sobre o assunto. Todavia, os resultados da presente pesquisa apontam que apenas 8 países publicaram 4 ou mais artigos, o que demonstra a dispersão dos dados sobre essa questão. Indica-se, nesse caso, o desenvolvimento de outras pesquisas de revisão que busquem analisar os livros, teses, dissertaçóes e literaturas cinzentas do mesmo período, no sentido de compreender o quanto esses dados podem ou não ser generalizados.

Sobre o Brasil, país que mais publicou artigos sobre o assunto (87 artigos), percebe-se que o aumento das publicaçóes aconteceu a partir dos anos 2000. Identifica-se que esses dados podem ser explicados quando se considera os importantes avanços na disseminaçáo do conhecimento em terapia ocupacional no contexto brasileiro, a partir da década de 1990, como a criação de periódicos científicos nacionais, o fortalecimento de eventos científicos de abrangência nacional e a criação de grupos de pesquisa (Folha, 2019; Lopes et al., 2016). Especificamente a respeito dos Cadernos de Terapia Ocupacional da UFSCar, a indexação do periódico só veio a ocorrer em 2012, acompanhada de maiores mudanças com relação à melhor qualificação acadêmica. Essas mudanças vêm repercutindo no aumento do número de textos publicados no periódico (Lopes et al., 2016).

Sobre as publicaçóes em periódicos nacionais específicos da área, estudos de Folha (2019) e de Folha et al. (2017) apontaram que mais da metade das publicaçóes dos terapeutas ocupacionais afiliados a instituiçóes brasileiras foi veiculada em periódicos que não são específicos da área. Entretanto, a realidade dos referidos estudos diverge substancialmente dos resultados da presente pesquisa, uma vez que, aqui, os resultados identificaram que apenas 3 artigos escritos por terapeutas ocupacionais brasileiros foram publicados em periódicos não específicos, no universo de 89 artigos publicados em português. São eles: Texto Contexto Enfermagem; Cogitare Enfermagem; e Ciência e Saúde Coletiva. Ademais, apenas 1 artigo publicado por terapeuta ocupacional brasileira em periódico internacional, porém específico, Occupational Therapy International.

A constataçáo de que este estudo diverge dos resultados daqueles mencionados anteriormente se constitui em um achado importante, demonstrando a necessidade de novas investigaçóes. Essa importância se justifica quando se percebe que os terapeutas ocupacionais brasileiros que pesquisam especificamente no campo da Saúde Mental vêm fortemente se dedicando a publicar suas produçóes em periódicos específicos da área. Assim, é possível inferir que esse grupo de terapeutas ocupacionais vêm se debruçando sobre a construção do conhecimento científico e das práticas em Saúde Mental, especificamente em interface com a terapia ocupacional.

Deve-se considerar que, ainda assim, apesar de ser interessante que os estudos sejam publicados em periódicos específicos, pensando na construção do conhecimento científico na área, as publicaçóes em periódicos de áreas afins não são menos importantes.

Cabe destacar aqui que a publicação sobre terapia ocupacional em periódicos de áreas afins é essencial para a divulgação do conhecimento produzido pela profissão, dado que a terapia ocupacional é uma profissão de caráter interdisciplinar, fazendo-se fundamental o diálogo com outros campos do conhecimento (Folha et al., 2019, p. 660).

Todavia, apesar da importância em publicar manuscritos em periódicos de áreas afins, gostaríamos de mencionar que, para que os periódicos específicos da área sejam fortalecidos e melhorem sua qualificação acadêmica, é necessário que os próprios terapeutas ocupacionais realizem esforços nesse sentido. Um maior investimento desses pesquisadores 
em produzir conhecimento em terapia ocupacional e em veiculá-los por meio de periódicos específicos poderia contribuir com um maior reconhecimento da terapia ocupacional como área. Esse reconhecimento, por sua vez, poderia auxiliar a respaldar a ideia de que existem saberes e práticas que são próprios desta profissão, embora estejam articulados a diversos campos, como o da Saúde Mental, por exemplo.

\section{Abordagem metodológica dos estudos}

Acerca dos métodos e procedimentos metodológicos dos estudos analisados, identificamos que, ao se desenvolver uma pesquisa científica, as principais abordagens metodológicas utilizadas são qualitativas e quantitativas (Minayo, 2014). Entretanto, existe a possibilidade da junçáo entre as duas abordagens, produzindo, assim, uma pesquisa considerada mista (Sampieri et al., 2006). Dos 249 artigos analisados, 89 (36\%) são de abordagem qualitativa, 28 (11\%) de abordagem quantitativa e 25 (10\%) de abordagem mista. Destacamos que 107 (43\%) estudos não definem, em nenhum momento do manuscrito, a abordagem da pesquisa. Informaçóes mais detalhadas sobre a abordagem metodológica poderão ser visualizadas no Tabela 3, a seguir.

Tabela 3. Distribuição dos artigos segundo a abordagem metodológica informada, idioma e ano de publicação.

\begin{tabular}{|c|c|c|c|c|c|c|c|}
\hline \multirow{2}{*}{$\begin{array}{l}\text { Abordagem } \\
\text { Metodológica }\end{array}$} & \multirow[b]{2}{*}{ Quantidade } & \multicolumn{3}{|c|}{ Idioma } & \multicolumn{3}{|c|}{ Ano de Publicaçáo } \\
\hline & & Inglês & Português & Espanhol & $\begin{array}{c}1990- \\
1999\end{array}$ & $\begin{array}{l}2000- \\
2009\end{array}$ & $\begin{array}{c}2010- \\
2018\end{array}$ \\
\hline Qualitativa & 89 & 41 & 44 & 4 & 7 & 11 & 71 \\
\hline Quantitativa & 28 & 21 & 7 & 0 & 1 & 2 & 25 \\
\hline Mista & 25 & 21 & 4 & 0 & 0 & 1 & 24 \\
\hline Não Especificada & 107 & 70 & 34 & 3 & 18 & 20 & 69 \\
\hline
\end{tabular}

Fonte: Elaboração própria, 2020.

Os resultados apontam que a maior parte dos estudos que descreveram a abordagem metodológica utilizada é qualitativa. Pensar em saúde e produzir conhecimento frente ao cuidado em saúde mental vai ao encontro da necessidade de entender o sujeito na sua singularidade, no seu espaço e miudezas, questóes que estão, na maioria das vezes, em consonância com uma abordagem metodológica qualitativa, que investiga processos subjetivos e interpretativos (Minayo, 2006; 2014).

Entendemos que o fato de a maioria dos estudos em terapia ocupacional e saúde mental utilizar da abordagem qualitativa pode estar vinculado à ideia de que tal abordagem possibilita um maior aprofundamento dos fenômenos sociais ou objetos estudados (Minayo, 2014). A utilização de metodologias qualitativas e de coletas de dados, centradas na opinião dos participantes da pesquisa e na observação de sua realidade, pode ser mais adequada em pesquisas sobre saúde mental (Souza \& Lussi, 2020).

Embora compreendendo que todas as abordagens sejam fundamentais para a construção do conhecimento, ressalta-se que a abordagem qualitativa permite "[...] levar em conta os níveis mais profundos das relaçóes sociais” (Minayo, 2006, p. 23), algo crucial para a compreensão do campo da saúde mental. 
De acordo com Minayo (2014, p. 57), "[...] as abordagens qualitativas se conformam melhor a investigaçóes de grupos e segmentos delimitados e focalizados, de histórias sociais sob a ótica dos atores [...]". Ainda, é importante ressaltar que não cabe aqui uma comparação entre as abordagens qualitativa e quantitativa, uma vez que cada uma delas tem seu lugar, sua adequaçáo e um importante papel na pesquisa (Minayo, 2014).

Ainda, ao identificar que $43 \%$ dos estudos não declararam sua abordagem metodológica, temse um limite para a pesquisa. Esclarecemos que a escolha por não designar em nossas tabelas a abordagem dos estudos sem que esta estivesse explicitamente declarada no texto original foi dada devido à preocupação das autoras em diminuir vieses da pesquisa, realizando um panorama científico de maneira mais fidedigna ao modo com que as pesquisas foram escritas.

\section{Objetos dos estudos}

Em relação aos objetos de estudo dos artigos analisados, estes foram analisados e categorizados pelas pesquisadoras após as leituras na íntegra e a obtençấo de consensos em relaçáa às categorias elencadas e a distribuição dos estudos entre elas. Foram identificadas 9 categorias (de "a" a "i"), que podem ser observadas na Figura 2, a seguir. Todos os artigos e as categorias na quais eles foram incluídos podem ser acessados por meio do QR Code disponibilizado na Figura 1.

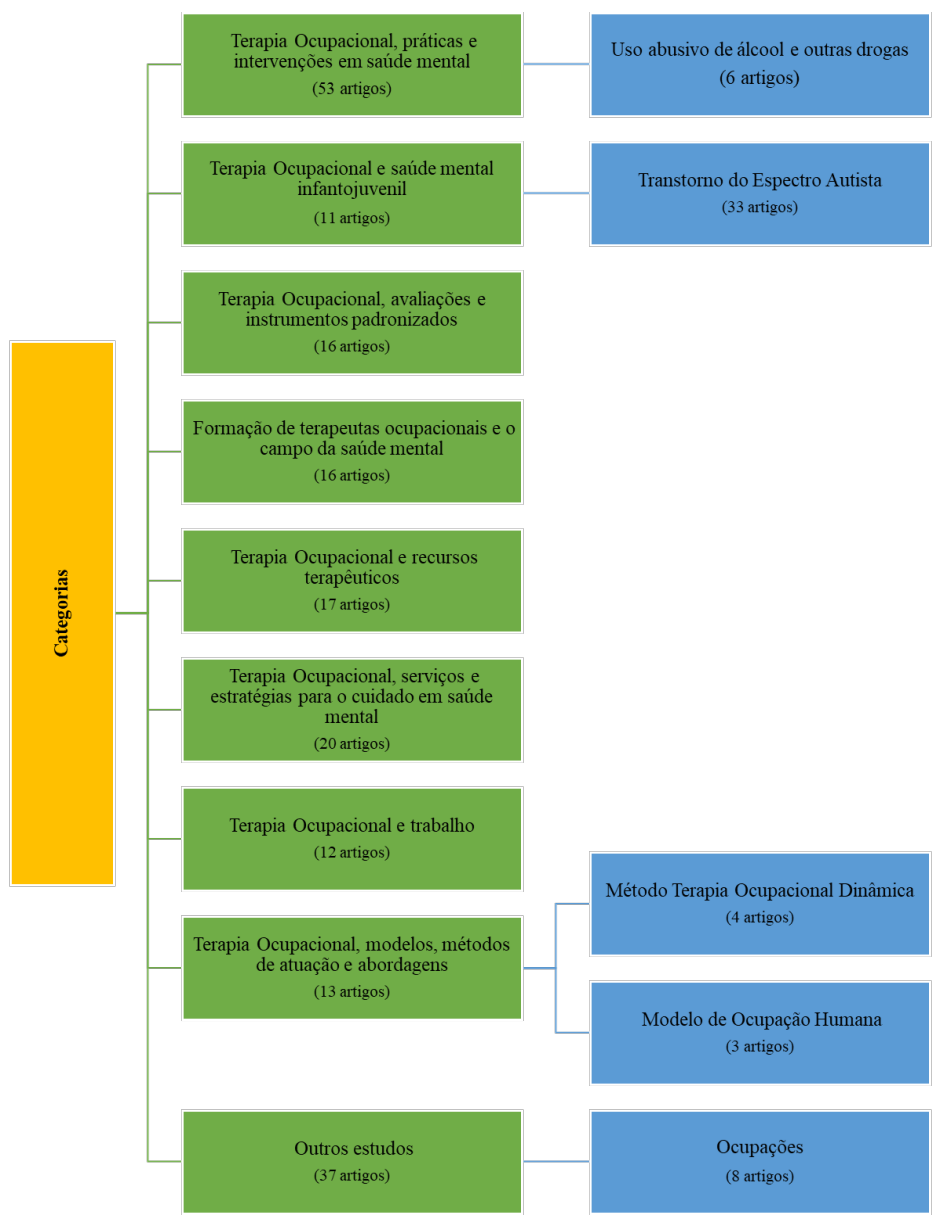

Figura 2. Fluxograma da categorização dos objetos de estudo. Fonte: Elaboração própria, 2020. 
a) Terapia ocupacional, práticas e intervençóes em saúde mental: Nesta categoria, foram incluídos 53 artigos, que discorrem sobre as diferentes intervençóes da terapia ocupacional em saúde mental, seja na atuação individual do terapeuta ocupacional, ou por meio de sua atuaçáo como membro de uma equipe multi/interprofissional (ver, com o QR Code, os artigos de número 1 a 53). De forma geral, são estudos que discorrem sobre: o raciocínio clínico do terapeuta ocupacional; sua inserção em espaços de acolhimento; troca e processos de escuta; sua atuação e as estratégias de cuidado dispensadas nos serviços especializados de atenção à saúde mental e as especificidades da atuação na área; a intervenção precoce em saúde mental; acompanhamento terapêutico utilizando a abordagem da terapia ocupacional em casos agudos, no pós-alta hospitalar, diante das questóes de gênero, da inclusão da pessoa com sofrimento psíquico e dos cuidados dispensados aos seus familiares. Nessa categoria, 6 estudos que se dedicam especificamente à temática do uso abusivo de álcool e outras drogas abordam o cotidiano e perspectivas desses sujeitos e as práticas de terapeutas ocupacionais nos Centros de Atenção Psicossocial Álcool e Drogas - CAPSad (ver, com o QR Code, os artigos de número: 54 a 59).

b) Terapia ocupacional e saúde mental infantojuvenil: Foram analisados 11 artigos sobre as questóes relacionadas ao sofrimento psíquico de crianças e adolescentes e a atuação da terapia ocupacional (ver, com o QR Code, os artigos de número: 60 a 70). São estudos sobre: a rede de cuidado à saúde mental de crianças e adolescentes; desempenho ocupacional de usuários de Centros de Atenção Psicossocial Infantojuvenil (CAPSij); práticas educativas parentais utilizadas no cotidiano desta população; prática centrada na família e na saúde mental infantojuvenil; e o primeiro surto e as internaçóes, sejam elas de curta ou longa permanência. Ressalta-se que aqui foram incluídos 33 artigos que abordam exclusivamente o Transtorno do Espectro Autista (TEA) na infância e/ou adolescência, embora muito mais relacionados à infância do que à adolescência (ver, com o QR Code, os artigos de número: 71 a 103). De forma geral, sáo estudos que: abordam os referenciais teóricos e as intervençóes que contribuem para a atuação do terapeuta ocupacional junto ao TEA; padróes e práticas destes profissionais na área; que abrangem os professores e familiares de crianças e adolescentes com TEA; que tratam da relação entre autismo e processamento sensorial; que propóem estratégias para melhora do comportamento alimentar seletivo, comunicação, rotina, engajamento e participação social de crianças com TEA; que expóem a importância da estimulação auditiva, integração sensorial, uso da ioga, programa de coaching baseado na ocupação para famílias, manejo de crianças com TEA no transporte familiar e a identificação precoce do TEA pelo terapeuta ocupacional.

c) Terapia ocupacional, avaliaçóes e instrumentos padronizados: Das publicaçóes analisadas, 16 artigos discutiam a avaliação em terapia ocupacional, bem como alguns instrumentos padronizados utilizados no âmbito da saúde mental (ver, com o QR Code, os artigos de número: 104 a 119). No que se refere especificamente à avaliação, são estudos que discorrem sobre as diferentes estratégias utilizadas pelos terapeutas ocupacionais, tanto dentro quanto fora dos serviços de assistência à saúde mental, avaliação das atividades instrumentais de vida diária, sistema de avaliação de pessoas com doença mental, sistema de avaliação para crianças com autismo, TDAH e desenvolvimento típico, além da avaliação de pessoas com sofrimento psíquico associado a deficiências cognitivas. São exemplos: instrumentos construídos pelos próprios profissionais durante sua prática; avaliação em outros contextos, como o domicílio; 
avaliação realizada por uma equipe por meio de grupos de acolhimento, entre outros. Já em relação aos instrumentos padronizados, são artigos que se dedicam, por exemplo, ao desenvolvimento e validação de instrumentos, tradução transcultural, utilização de protocolos específicos para pessoas com depressão e ansiedade, utilização de um software que auxilia estudantes de terapia ocupacional no desenvolvimento do raciocínio clínico, avaliação das propriedades psicométricas de determinado instrumento para uso com pessoas com problemas de saúde mental, utilização de um modelo clínico em saúde mental - o COPES. São exemplos desses instrumentos: Kohlman Evaluation of Living Skills (ver, com o QR Code, o artigo 107), VALPAR Pro3000 (ver, com o QR Code, o artigo 109), 13-Item Satisfaction with Daily Occupations Scale (ver, com o QR Code, o artigo 115), Occupational Circumstances Interview and Rating Scale - Sweden (OCAIRS-S V2) (ver, com o QR Code, o artigo 119), entre outros.

d) Formaçáo de terapeutas ocupacionais e o campo da saúde mental: Foram selecionados 16 artigos relacionados à formação de terapeutas ocupacionais voltada à atuação em saúde mental (ver, com o QR Code, os artigos de número: 120 a 135). Abordam perspectivas e expectativas de estudantes de terapia ocupacional sobre a atuação em saúde mental, processo ensino-aprendizagem no campo da saúde mental, currículo e formação em saúde mental. Alguns relatos de experiências práticas relacionadas aos estágios na área, ensino de terapia ocupacional no contexto da dependência química, suicídio e a influência dos estágios em saúde mental sobre as práticas posteriores dos estudantes de terapia ocupacional.

e) Terapia ocupacional e recursos terapêuticos: Entre os estudos, 17 artigos apresentam relatos dos mais variados recursos terapêuticos utilizados em intervençóes da terapia ocupacional no campo da saúde mental (ver, com o QR Code, os artigos de número: 136 a 152). São alguns exemplos: atividades/ intervençóes grupais, oficinas, teatro espontâneo do cotidiano, uso da arte e atividades criativas, seja na forma de música, teatro, cinema, bricolagem, culinária e artesanato, além de salas sensoriais como recursos.

f) Terapia ocupacional, serviços e estratégias para o cuidado em saúde mental: Foram analisados 20 estudos que discorrem especificamente sobre os serviços especializados no cuidado à saúde mental e descrevem os contextos do cuidado adotado por terapeutas ocupacionais (ver, com o QR Code, os artigos de número: 153 a 172). De forma geral, analisam a rede de saúde mental e a estrutura dos serviços para a saúde mental, a interconsulta psiquiátrica, cuidado em saúde mental na atenção básica à saúde e a assistência oferecida no: hospital-dia, centro-dia, centro de convivência, hospital psiquiátrico, atuação nas residências terapêuticas, em hospitais de custódia.

g) Terapia ocupacional e trabalho: Foram identificados 12 estudos que discorrem sobre questóes relacionadas ao trabalho e à geração de renda de pessoas com sofrimento psíquico e a intervenção da terapia ocupacional (ver, com o QR Code, os artigos de número: 173 a 184). Exploram as potencialidades e dificuldades das iniciativas e/ou grupos de trabalho e geração de renda, a relação da terapia ocupacional com essas iniciativas e suas práticas, além do desempenho profissional de pessoas com sofrimento psíquico, o retorno ao trabalho e programas de treinamento profissional para esses sujeitos.

h) Terapia ocupacional, modelos, métodos de atuaçáo e abordagens: Aponta-se que 13 estudos discorrem sobre alguns modelos, métodos de atuaçáo e abordagens utilizadas por terapeutas ocupacionais no campo da saúde mental. Não se tem aqui a intençáo de 
diferenciar modelo, método de atuação e abordagem, e, sim, exemplificar os estudos que tratam sobre essas questóes (ver, com o QR Code, os artigos de número: 185 a 197). Alguns exemplos: intervenção multimodal, Medida de Desempenho Canadense, Tratamento Assertivo da Comunidade, Prática Centrada no Cliente, Modelo Kawa, Flow Theory, Prática Baseada em Evidências, além de modelos de terapia ocupacional para as diversas perspectivas da qualidade de vida e modelo de intervençáo tradicional em saúde mental e os modelos inter/transdisciplinares. Nessa categoria, 4 estudos estão especificamente ancorados no Método Terapia Ocupacional Dinâmica (MTOD) e abordam: a relação triádica; a aplicaçáo do MTOD em um caso; abordagem psicodinâmica na terapia ocupacional em saúde mental; e a supervisão de alunos à luz do MTOD (ver, com o QR Code, os artigos de número: 198 a 201). Ainda, 3 estudos estão fundamentados no Modelo da Ocupação Humana (MOHO) e discorrem sobre: a percepção dos terapeutas ocupacionais sobre a relevância prática do Modelo da Ocupação Humana $(\mathrm{MOH})$; o engajamento de pessoas com esquizofrenia à luz do $\mathrm{MOH}$; e o impacto do $\mathrm{MOH}$ sobre o paciente (ver, com o QR Code, os artigos de número: 202 a 204).

i) Outros estudos: Identificamos, ainda, 37 estudos cuja singularidade dificulta a categorização, tendo sido agrupados nesta categoria (ver, com o QR Code, os artigos de número: 205 a 241). Citamos alguns exemplos: reflexóes sobre estigma; recovery; resiliência de terapeutas ocupacionais; diálogo entre reabilitação psicossocial e terapia ocupacional; uso do trabalho como recurso terapêutico ao longo da história; diálogo entre as proposiçóes da Terapia Ocupacional centrada no cliente e autores da desinstitucionalização italiana; reflexão teórica sobre o conceito de justiça e sua interface com a terapia ocupacional; mulheres em sofrimento psíquico em contexto de pobreza; comportamentos de estilos de vida que podem trazer uma opçáo de baixo custo para o tratamento do transtorno do pânico; participação em um grupo de futebol comunitário e os benefícios aos seus integrantes; atuação do terapeuta ocupacional com imigrantes; cultura nos contextos de saúde mental; cooperação entre curandeiros tradicionais e terapeutas ocupacionais; terapia ocupacional na prática forense no Canadá; possibilidade de intervenção da terapia ocupacional com astronautas, entre outros. Nesta categoria, ainda foram identificados 8 estudos que refletem especificamente sobre as ocupações: a participação em ocupações significativas; o valor da ocupação como objetivo de intervenção; as necessidades ocupacionais de pessoas com sofrimento psíquico e as dificuldades ocupacionais geradas pelo sofrimento psíquico. Além disso, há também estudos que abordam o uso terapêutico da ocupação para habilitar pessoas no campo da saúde mental (ver, com o QR Code, os artigos de número: 242 a 249).

Diante dos resultados apresentados, é possível identificar um crescimento, nas últimas décadas, das produçóes sobre terapia ocupacional e saúde mental, demonstrando uma tentativa de fortalecimento deste campo via publicação acadêmica e científica.

É possível, ainda, extrair, por meio de identificação das mudanças reflexivas que ocorrem ao longo dos anos, que se trata de uma disciplina viva, que lida com seres humanos, e, portanto, sujeita a novas possibilidades prático-teóricas. Como exemplo dessa dinamicidade, destacam-se as reflexóes no campo da saúde mental na infância e adolescência, que vêm se desvinculando do que é preconizado para o adulto, inclusive refletindo sobre diferenciaçóes desse grande complexo "infância-adolescência" (Fernandes et al., 2020); o uso de atividade, que passa a ser permeado por atravessamentos culturais, e nutridos por questóes sociopolíticas, representando possibilidades de 
emancipação, cidadania e participação (Ribeiro \& Machado, 2008); e das próprias questóes de álcool e outras drogas e trabalho que são fortemente atravessadas por questóes políticas.

\section{Consideraçóes Finais}

Considera-se que o estudo respondeu aos objetivos propostos, descrevendo o panorama do conhecimento científico sobre terapia ocupacional e saúde mental em uma janela de produçóes científicas de 28 anos. Desta forma, o presente estudo contribui para a identificação de estudos realizados na área, evidenciando os avanços ao longo do tempo.

Complementarmente, os resultados aqui apresentados auxiliam na compreensão e aprimoramento das açóes do campo da terapia ocupacional, assim como indicam a relevância da profissão nas diferentes nuances do campo.

Dentre os achados, destacamos a alta incidência de artigos publicados na língua inglesa, ressaltando a diversidade de países que fazem uso desse idioma para as publicações, com destaque para os Estados Unidos, Austrália e Canadá. Evidenciamos, ainda, a significativa produção brasileira. Os resultados demonstraram aumento significativo das publicaçóes científicas, especialmente a partir da década de 2000, e o elevado número de produçóes que fazem uso da abordagem qualitativa.

Com a elaboração deste levantamento, bem como da construção de categorias dos objetos de estudos, foi possível auxiliar o detalhamento e a compreensão da construção do conhecimento em terapia ocupacional e saúde mental no Brasil e no Mundo. Compreendese que esta produção, até hoje, é anglófona, devido à origem da profissão, contada por meio da história oficial. E, por meio desta reflexão, foi possível visibilizar publicaçóes de autores que têm afiliações profissionais diversas e que realizam pesquisas e práticas profissionais importantes, em diferentes partes do mundo. Além disso, este estudo possibilitou a identificação de interesses e tendências de pesquisas da profissão.

O objetivo deste estudo não visava ao aprofundamento de cada categoria de objetos dos estudos, no entanto, com esta fotografia do percurso realizado pela produção teórica da terapia ocupacional foi possível auxiliar na compreensão e no aprimoramento das açóes do núcleo da terapia ocupacional, assim como indicam a relevância da profissão nas diferentes nuances do campo.

Como limitação deste levantamento, enfatizamos que a literatura cinza não foi contemplada. Sugerimos, ainda, a realização de estudos futuros para o acompanhamento das produçóes e tendências na área de terapia ocupacional e saúde mental, além da realização de mapeamentos em outros campos da terapia ocupacional, com o objetivo de identificar em quais periódicos os pesquisadores vêm publicando seus estudos, uma vez que observamos que grande parte dos estudos da saúde mental foram publicados em periódicos específicos e outros estudos demonstraram uma realidade diferente, apontando para muitas publicaçóes de terapeutas ocupacionais em periódicos de áreas afins.

Acerca das lacunas científicas, apontamos para a escassez de estudos que são participativos (por participativo se entende aqueles estudos que investigam as experiências "com" os usuários de serviços de saúde mental e não "sobre" eles). Os resultados da presente revisão apontam para uma maior permanência de estudos que focalizam os diagnósticos e intervençóes sem, muitas vezes, compreenderem, primeiramente, as realidades e experiências singulares dos sujeitos e coletivos. Assim, ainda que o desenvolvimento de estudos nas mais variadas perspectivas teóricas seja importante para engrandecer as 
discussóes sobre a temática, foi perceptível que a literatura científica, sobretudo a internacional, carece de pesquisas que têm como direcionamento teórico o reconhecimento do protagonismo de grupos marginalizados, cotidianidades limitadas, além de valorização de competências. Acreditamos que considerar questóes como essas é estar em consonância com o respeito às subjetividades e diversidades.

\section{Referências}

Almeida, D. T., \& Trevisan, E. R. (2010). Estratégias de intervenção da terapia ocupacional em consonância com as transformaçóes da assistência em saúde mental no Brasil. Interface: Comunicação, Saúde, Educação, 15(36), 299-308.

Amarante, P. (2007). Saúde mental e atenção psicossocial. Rio de Janeiro: Editora FIOCRUZ.

Brilhante, A. V. M., Moreira, G. A. R., Vieira, L. J. E. S., \& Catrib, A. M. F. (2016). Um estudo bibliométrico sobre a violência de gênero. Saúde e Sociedade, 25(3), 703-715. http://dx.doi.org/10.1590/s0104-12902016148937.

Cintra, P. R., Silva, M. D. P., \& Furnival, A. C. (2020). Uso do inglês como estratégia de internacionalização da produção científica em Ciências Sociais Aplicadas: estudo de caso na SciELO Brasil. Questão, 26(1), 17-41.

Fernandes, A. D. S. A., Matsukura, T. S., Lussi, I. A. O., Ferigato, S. H., \& Morato, G. G. (2020). Reflexões sobre a atençáo psicossocial no campo da saúde mental infantojuvenil. Cadernos Brasileiros de Terapia Ocupacional, 28(2), 725-740.

Folha, O. A. A. C. (2019). A terapia ocupacional como campo de conhecimento científico no Brasil: formação pós-graduada e atuação profissional de seus mestres e doutores (Tese de doutorado). Universidade Federal de São Carlos, São Carlos.

Folha, O. A. A. C., Folha, D. R. S. C., Cruz, D. M. C., Barba, P. C. S. D., \& Emmel, M. L. G. (2019). Caracterização de publicações científicas sobre terapia ocupacional em periódicos não específicos da profissão no período de 2004 a 2015. Cadernos Brasileiros de Terapia Ocupacional, 27(3), 650-662.

Folha, O., Cruz, D., \& Emmel, M. L. G. (2017). Mapeamento de artigos publicados por terapeutas ocupacionais brasileiros em periódicos indexados em bases de dados. Revista de Terapia Ocupacional da Universidade de São Paulo, 28(3), 358-367. Recuperado em 12 de setembro de 2021, de https://www.revistas.usp.br/rto/article/view/135218

Guajardo Córdoba, A. G., \& Galheigo, S. M. (2015). Reflexiones críticas acerca de los derechos humanos: contribuciones desde la terapia ocupacional Latinoamericana. World Federation of Occupational Therapists Bulletin, 71(2), 73-80.

Hahn, M., \& Pinto, J. (1997). Tendências atuais da terapia ocupacional internacional na prática. Cadernos de Terapia Ocupacional da UFSCar, 6(1), 1-12.

Hayashi, C. R. M. (2013). Dossiê Epistemologia e Teorias da Educação: apontamentos sobre a coleta de dados em estudos bibliométricos e cientométricos. Filosofia e Educação, 5(2), 89-102.

Lopes, R. E., Duarte, M. L. M. C., Pereira, B. P., Oliver, F. C., \& Malfitano, A. P. S. (2016). A divulgaçáo do conhecimento em terapia ocupacional no Brasil: um retrato nos seus periódicos. Cadernos Brasileiros de Terapia Ocupacional, 24(4), 777-789.

Magalhães, L. (2013). Ocupação e atividade: tendências e tensões conceituais na literatura anglófona da terapia ocupacional e da ciência ocupacional. Cadernos Brasileiros de Terapia Ocupacional, 21(2), 255263.

Malfitano, A. P. S., Matsukura, T. S., Martinez, C. M. S., Emmel, M. L. G, \& Lopes, R. E. (2013). Programa de pós-graduação stricto sensu em terapia ocupacional: fortalecimento e expansão da produção de conhecimento na área. Revista Brasileira de Atividade Física \& Saúde, 18(1), 105-111.

Mângia, E. F. (1999). Terapia ocupacional: práticas, discursos e a questão da legitimidade científica. Revista de Terapia Ocupacional da USP, 10(2-3), 55-59. 
Minayo, M. D. S. (2006). O desafio do conhecimento: pesquisa qualitativa em saúde. São Paulo: Hucitec.

Minayo, M. D. S. (2014). O desafio do conhecimento: pesquisa qualitativa em saúde. São Paulo: Hucitec.

Morato, G. G., \& Lussi, I. A. O. (2018). Contribuiçôes da perspectiva de Reabilitação Psicossocial para a terapia ocupacional no campo da saúde mental. Cadernos Brasileiros de Terapia Ocupacional, 26(4), 943951.

Pimenta, A. A., Portela, A., Oliveira, C., \& Ribeiro, R. M. (2017). A bibliometria nas pesquisas acadêmicas. Scientia, 4(7), 1-13.

Ribeiro, M. B. S., \& Oliveira, L. R. (2005). Terapia ocupacional e saúde mental: construindo lugares de inclusão social. Interface: Comunicação, Saúde, Educação, 9(17), 425-431.

Ribeiro, M. C., \& Machado, A. L. (2008). A terapia ocupacional e as novas formas do cuidar em saúde mental. Revista de Terapia Ocupacional da Universidade de Sáo Paulo, 19(2), 72-75.

Ricci, T. E., Marques, I. P., \& Marcolino, T. Q. (2018). Terapia ocupacional em saúde mental nos congressos brasileiros: uma revisão de escopo. Cadernos Brasileiros de Terapia Ocupacional, 26(4), $915-$ 925 .

Sampieri, R. H., Collado, C. H., \& Lucio, P. B. (2006). Metodologia de pesquisa. São Paulo: McGraw-Hill.

Silva, J. H., \& Hayashi, M. C. P. I. (2018). Estudo bibliométrico da produção científica sobre a associação de pais e amigos dos excepcionais. Revista Educação Especial, 31(60), 65-80.

Souza, M. B. C. A., \& Lussi, I. A. O. (2020). Juventude, trabalho informal e saúde mental. Revista de Ciências Sociais Politica \& Trabalho, (51), 126-144. http://dx.doi.org/10.22478/ufpb.1517$5901.0 v 51 \mathrm{n} 0.48293$.

Volpato, G. L. (2015). O método lógico para redação científica. Revista Eletrônica de Comunicação, Informação e Inovação em Saúde, 9(1), 1-14. http://dx.doi.org/10.29397/reciis.v9i1.932.

\section{Contribuiçáo dos Autores}

Concepção e desenvolvimento de todas as etapas da pesquisa (planejamento e concepção; busca, organização e revisão das fontes; organização e revisão dos dados; organização e revisão dos resultados; escrita do texto): Bárbara de Fátima Depole, Danieli Amanda Gasparini, Erika Regina de Oliveira Colato, Laysla Demonari Gomes, Lisabelle Manente Mazaro, Marina Batista Chaves Azevedo de Souza e Thaís Thaler Souza. Concepção e planejamento da pesquisa, orientação de todas as etapas e revisão crítica do texto: Isabela Aparecida de Oliveira Lussie Thelma Simóes Matsukura. Todos os autores aprovaram a versão final do texto.

\section{Fonte de Financiamento}

Esta pesquisa foi financiada pela CAPES - Coordenação de Aperfeiçoamento de Pessoal de Nível Superior - Código 001.

\section{Autor para correspondência}

Lisabelle Manente Mazaro

e-mail: lisabellemazaro@hotmail.com

\section{Editor de seçáo}

Prof. Dr. Vagner dos Santos 